\title{
A Response to Christopher Hood: 'The ethics of personal genetic profiling'
}

\section{RICHARD TUTTON AND ADAM HEDGECOE ${ }^{1}$}

One aspect of the recently published Nuffield Council on Bioethics' report on Medical Profiling and Online Medicine centred on the development of direct-toconsumer (DTC) personal genomic services, and is the focus of Hood's commentary in this issue of GSP. We have been prompted to make a number of comments in response to this piece (rather than to the report in its entirety). We would first like to state clearly that the work of the Nuffield group is welcomed and its report is a very useful contribution to ongoing discussions amongst academics, policy makers, and public interest groups about developments in the personalisation and online provision of various healthcare products and services.

Online services offering direct-to-consumer genetic testing have been around for about a decade or so now and have been growing in number. It is important to note that those companies which have tended to grab the headlines in the last few years, namely those offering personal genomics services such as 23andMe, Navigenics, deCODEMe, and Pathway Genomics, are only one part of a dynamic commercial sector in which companies have developed distinctive business models and specialise in different genetic testing services. A survey conducted by Cesagen in August 2010 indicated that, at that time at least, there were 69 services offering genetic testing to consumers for a wide range of purposes. These included: providing information on future disease susceptibility and drug metabolism, diagnosing existing gene disorders, providing advice on physical exercise, nutrition and lifestyle choices based on analysis of DNA, and offering information about genetic relationships or ancestry. While Hood focuses exclusively on susceptibility testing services that provide estimates to individuals of their risk of developing future disease, many of the same companies as well as others also offer carrier and prenatal diagnostic testing to consumers. The market therefore is a heterogeneous one and this needs to be recognised by policy advisors in their investigations and recommendations.

\section{Determining the Problem and the Lack of Evidence}

Although we agree with Hood that there is "little evidence available about the number of people buying these services", we feel that the claim that there is little evidence about "the harms (or benefits) they experience from taking the tests" is inaccurate. While we may not have very much specific data on DTC testing yet, psychosocial research into the impact of genetic susceptibility testing goes back over a decade. While this research highlights the complex and unpredictable nature of people's response to this kind of information, it is also clear that: "threat representations that include genetic causes are often seen as ones that are less controllable than threats with behavioural or environmental causes". ${ }^{2}$ For example, in the case of counselling 
designed to persuade people to give up smoking, "genetic feedback may heighten vulnerability and possibly promote distress, but may not immediately enhance quitting in most smokers". ${ }^{3}$ This literature should not be neglected; indeed, it should be engaged with by policy advisors when considering the issue of DTC testing, to draw out its implications for society as a whole. The picture is further complicated by Bloss et al, who very recently reported that, based on their research, the impact on individuals' health behaviour from the information they gain from a DTC personal genome service appears to be very limited. ${ }^{4}$

\section{Regulation and International Developments}

The focus of Hood's commentary was very much the UK context, but of course these sociotechnical developments are international in character, especially given the widespread use of the internet to purchase DTC tests, and so the international context is also important. At the European Union level, the 1998 Directive on in vitro diagnostic medical devices (known as IVDD, 98/79/EC) sets a series of standards for the manufacture, supply, labelling, safety and performance of in vitro diagnostic medical devices, including genetic tests. ${ }^{5}$ The IVDD, however, has limited application in relation to DTC testing since it does not apply to 'in-house' tests developed by laboratories for their own use, which many DTC tests qualify as being, and defers to member states to set their own laws on the supply of medical devices. France, Switzerland and Germany have all made private genetic testing without physician approval illegal, while the UK and the Netherlands have not, so there are differing views amongst European countries. In June 2010 the European Commission opened a consultation on revising the IVDD and asked specifically whether additional requirements or restrictions for DTC genetic tests are required. This planned revision of the IVDD builds on work undertaken by the Global Harmonization Task Force (GHTF) which has developed a new risk classification scheme that could lead to new genetic tests being subject to independent premarket review.

Furthermore, in 2008, the Council of Europe approved an additional protocol to the Convention on Human Rights and Biomedicine of 1997, which states that "clinical utility of a genetic test shall be an essential criterion for deciding to offer this test to a person or a group of persons" (article 6) and that "a genetic test for health purposes may only be performed under individualised medical supervision" (article 7). ${ }^{6}$ It is not clear that to date all signatories to the Convention have signed up to the new protocol, and it should be noted that the UK, along with 20 of the 47 members of the Council of Europe, has not signed and ratified the Convention.

As Hogarth et al observed a few years ago: "It is unlikely that we will see the emergence of a common, harmonized approach to DTC testing" " but in the last year we are beginning to see a more joined-up approach to DTC regulation from US and European Union authorities. Much depends on what the US authorities decide to do in relation to DTC genetic testing, since most of the industry is located in that country and we are awaiting the outcome of recent interventions by the US Food and Drug Administration in this area to see what will change in terms of how DTC tests are 
regulated. However, with the launch of new companies in South Korea, Australia, and India, the personal genomics industry is becoming more globalised. It certainly looks set to be more than a temporary phenomenon and will need to be revisited in the near future.

${ }^{1}$ Cesagen, the ESRC Centre for Economic and Social Aspects of Genomics, University of Cardiff and University of Lancaster. r.tutton@lancaster.ac.uk

${ }^{2}$ T.M. Marteau and J. Weinmann. Self-regulation and the Behavioural Response to DNA Risk Information: A Theoretical Analysis and Framework for Future Research. Social Science \& Medicine 2006; 62: 1360-1368.

${ }^{3}$ C. Lerman et al. Incorporating Biomarkers of Exposure and Genetic Susceptibility Into Smoking Cessation Treatment: Effects on Smoking-Related Cognitions, Emotions, and Behavior Change. Health Psychology 1997; 16 (1): 87-99.

${ }^{4}$ C.S. Bloss et al. Consumer Perceptions of Direct-to-Consumer Personalized Genomic Risk Assessments. Genetics in Medicine 2011; 12 (9): 556-566.

${ }^{5}$ http://ec.europa.eu/enterprise/policies/european-standards/documents/harmonised-standardslegislation/list-references/iv-diagnostic-medical-devices/index_en.htm (accessed 7 April 2011)

${ }^{6}$ Council of Europe. 2008. Additional Protocol to the Convention on Human Rights and Biomedicine, concerning Genetic Testing for Health Purposes. Strasbourg.

http://conventions.coe.int/Treaty/en/Treaties/html/203.htm (accessed 5 April 2011)

${ }^{7}$ S. Hogarth et al. The Current Landscape for Direct-to-Consumer Genetic Testing: Legal, Ethical and Policy Issues. Annual Review of Genomics and Human Genetics 2008; 9: 161-82. 